\title{
Pink spot with an internal resorption: case report
}

\begin{abstract}
Introduction: The teeth resorption can occur in the root canal or in the crown. The first one are relatively common and the pink spots in the teeth were first described by Mummery in 1920. Resorption can be classified as internal and external resorption and the internal it is described as a rare occurrence as compared to external.
\end{abstract}

Case report: this article describes a pink spot that was diagnosed as an internal resorption. The teeth showed with low probability to resist an orthodontic treatment and had to be extracted.

Keywords: pink spot, teeth resorption, unerupted tooth
Volume 8 Issue $3-2017$

\author{
Natalia Myrrha Melo,' Leandro Junqueira \\ de Oliveira, ${ }^{2}$ Claudia Assuncao e Alves \\ Cardoso,' Martinho Campolina Rebello \\ Horta,' Carlos Roberto Martins,' Flavio \\ Ricardo Manzi' \\ 'Department of Oral Radiology, Pontifical Catholic University of \\ Minas Gerais, Brazil \\ ${ }^{2}$ Postgraduate program of Pontifical Catholic University of Minas \\ Gerais, Brazil
}

\author{
Correspondence: Flavio Ricardo Manzi, Department of Oral \\ Pathology, Pontifical Catholic University of Minas Gerais, Av. \\ Dom Jose Gaspar, 500/Predio 46 -Coracao Eucarnstico-Belo \\ Horizonte/MG, CEP 30535-901, Brazil, \\ Email manzi@pucminas.br
}

Received: September 25, 2017 | Published: September 28 2017 


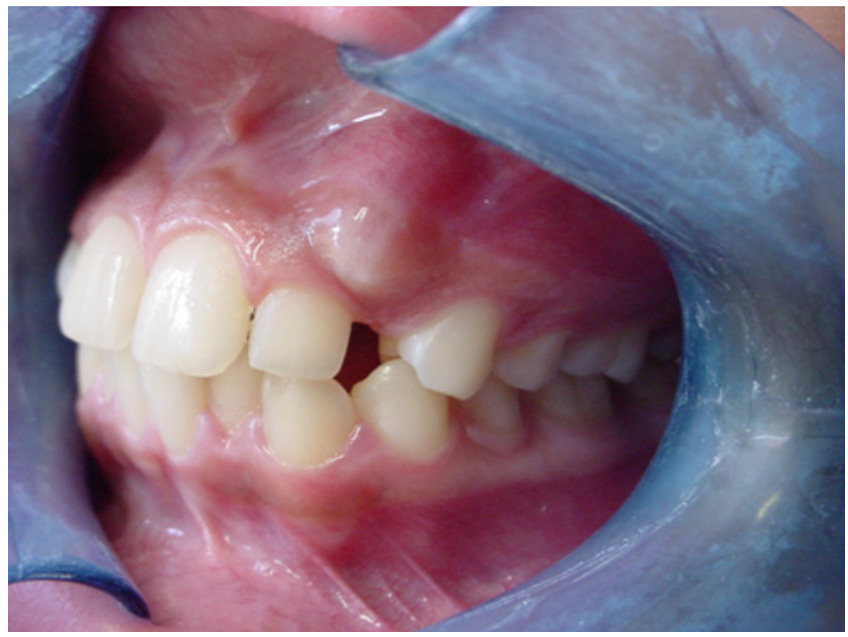

Figure I Absence on the left maxillary canine and a swelling in its region.
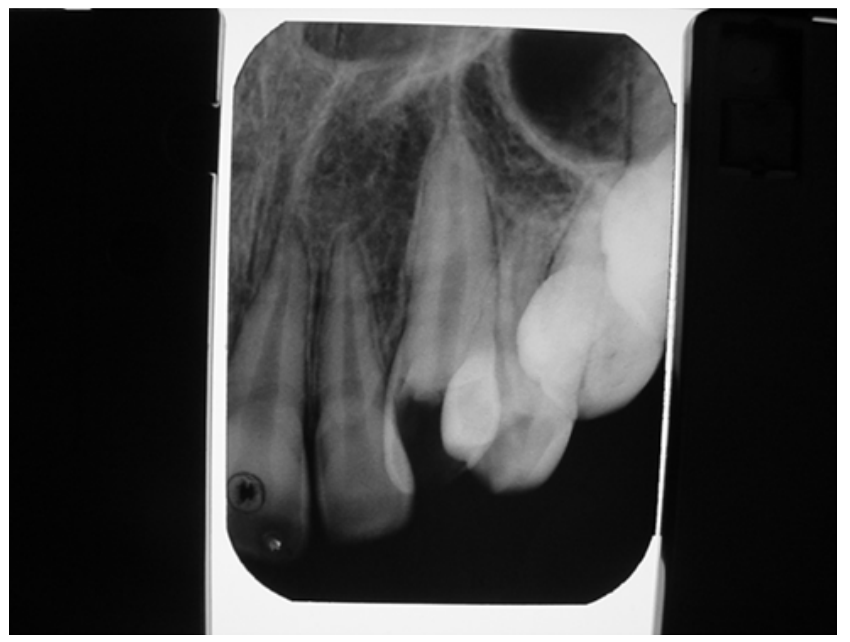

Figure 2 The internal resorption involved the dentin and part of the enamel on this crown.

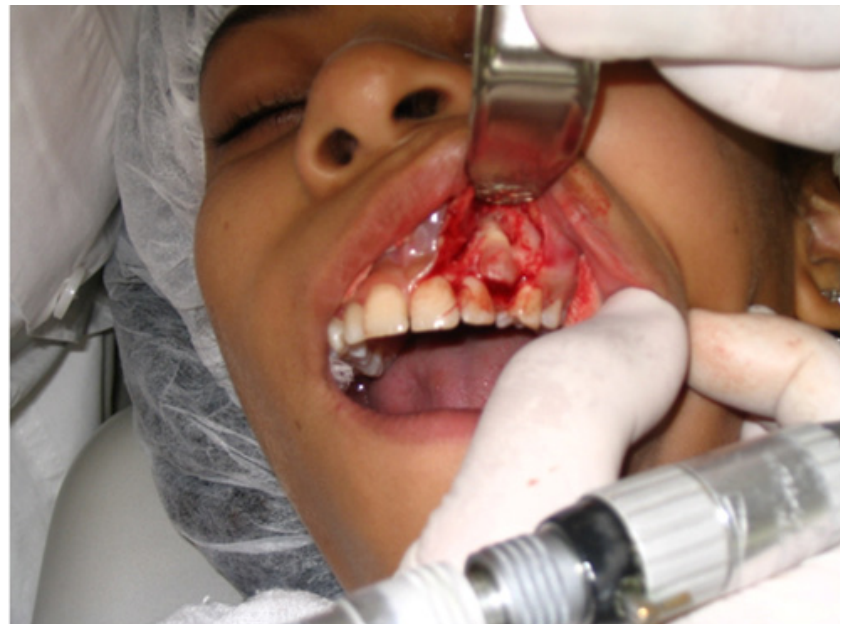

Figure 3 Surgery procedure: It was possible to observe that the crown tooth was pink.

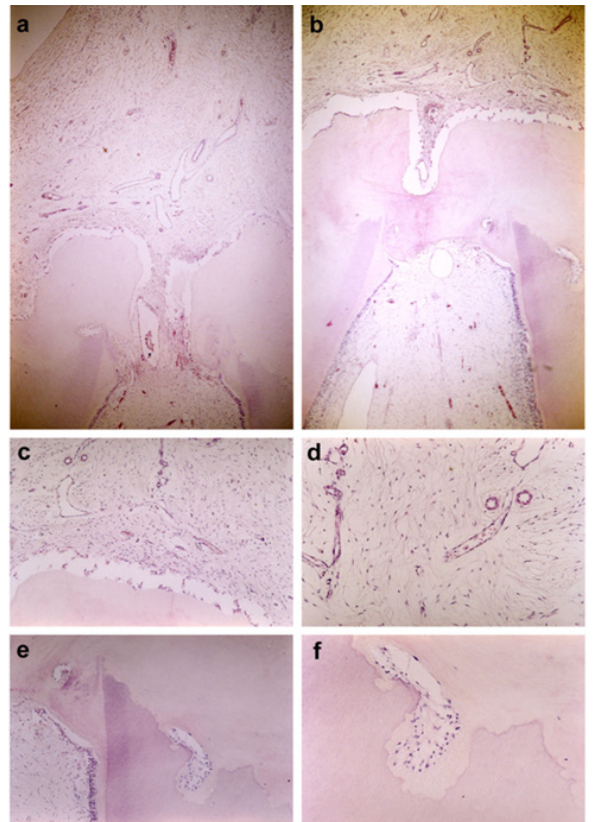

Figure 4 Histopathological features. Tooth fragment showing that coronary dentin (D) was reabsorbed and replaced by loose fibrous connective tissue (C). An area of deposition of amorphous acidophilic mineralized material (M) on the reabsorbed dentin region $(D)$ was also observed. The normal dental pulp can also be found (P) ( $a$ and b, HE X40; c and e, HE XI00; d and f, HE $\mathrm{X} 400$ ).

\section{Discussion}

Teeth resorption is a condition associated with either a physiologic or a pathologic process resulting in a loss of dentin or cementum. Such resorption may occur in root canal or in crown, classified as external or internal. The crown resorption is less common than root resorption. ${ }^{1}$ Additionally, internal resorption is much less common than external one. ${ }^{3}$ They can occur in primary or permanent dentition. However internal resorption is rare in permanent teeth. ${ }^{2}$ Thus the present case joins rare condition of tooth resorption, since it presents intracoronal resorption in an unerupted permanent tooth. Ne et al. ${ }^{2}$ affirmed that tooth resorption results from injuries to or irritation of the periodontal ligament and/or tooth pulp, as traumatic laxation injuries, orthodontic tooth movement or chronic infections of the pulp or periodontal structures. Eveson \& Gibb. ${ }^{3}$ also indicated various factors as etiology of internal resorption, including vascular changes, acute trauma, restorative procedures, and orthodontic treatment. However, they reported a case, which they considered idiopathic. O'Neal et al. ${ }^{1}$ defended various theories as etiology of intracoronal resorptions of an unerupted tooth: apical inflammation of a primary precursor affecting the permanent successor; dental caries, which has not been proven can develop in an unerupted tooth; developmental abnormality of enamel or dentin causing hipoplasia or as an inclusion of uncalcified enamel matrix; internal resorption initiating within the pulp cavity or external resorption initiating in the periodontium. Solomon et al. ${ }^{9}$ described a case where internal resorption were discovered in two teeth after herpes zoster. The authors suggested the hipothesis that idiopathic internal resorption might be related to viral etiology. However Klambani et al. ${ }^{10}$ defended that etiology of 
internal resorption is largely unknown. The etiology of present case was considered idiopathic resorption once the patient was not related injuries or other important factor. Gowda. ${ }^{11}$ in 2015 related two cases about pink teeth with similar variation in the color intensity from region to region and they noted more intense discoloration along cervical region compared to the incised region. Similar to Gowda's study, ${ }^{11}$ this present article report a case showed pink discoloration in the dentin and enamel and cementum. Thomas et al. ${ }^{12}$ described the etiology and pathophysiology mechanisms involved in internal root resorption and they conclude that the prognosis is good for small lesions and when it have a early diagnostic. In our study the diagnostic was latter discovered with an internal resorption involved the dentin and part of the enamel resulting in the extraction. The present report describes a rare case where the internal resorption involved the dentin and part of the enamel on the crown. The treatment resulted in the extraction. After the surgery the patient went to the orthodontic treatment. If they had a early diagnostic, it maybe could prevent the fast progress and the tooth permanence. It is very important the early diagnostic by the dentist to propose the best treatment and prevent the tooth looser.

\section{Acknowledgments}

None.

\section{Conflicts of interest}

The authors declare that they have no conflict of interest and the patient provided an informed consent.

\section{Funding}

None.

\section{References}

1. O’Neal KM, Gound TG, Cohen DM. Preeruptive idiopathic coronal resorption: a case report. J Endod. 1997;23(1):58-59.

2. Ne RF, Witherspoon DE, Gutmann JL. Tooth resorption. Quintessence Int. 1999;30(1):9-25.

3. Eveson JW, Gibb DH. Multiple idiopathic internal resorption. Br Dent J. 1989;21(2):49-50.

4. Skillen WG. So-called intra-follicular caries. Dent J. 1941;10:307-308.

5. Kronfeld R. Histopathology of the teeth and their surrounding structures. JAMA. 1995;4:283-284.

6. Mummary JH. Some further cases of chronic perforating hyperplasia of the pulp. Brit Dent J. 1926;47:1-811.

7. Roy P, Fuks A. Pink Spot, Literature Review and Case Report. The Journal of Clinical Pediatric Dentistry. 2016;40(5):353-355.

8. White SC, Pharoah MJ. Oral Radiology: principles and interpretation. $4^{\text {th }}$ ed. Mosby: USA. 2000. p. 1-329.

9. Solomon CS, Coffiner MO, Chalfin HE. Herpes zoster revisited: implicated in root resorption. J Endod. 1986;12(5):210-213.

10. Klambani M, Lussi A, Ruf S. Radiolucent lesion of an unerupted mandibular molar. Am J Orthod Dentofacial Orthop. 2005;127(1):67-71.

11. Gowda BKC, Sivapathasundharam B, Chatterji A, et al. Histological Appearance of postmortem pink teeth: Reposrt of two cases. J Forensic Dent Sci. 2015;7(2):168-170.

12. Thomas P, Pillai RK, Ramakrishnan BP, et al. An insight into internal resorption. ISRN Dentistry ID 759326. 2014;1-7. 